\title{
PROGRAMAS DE
}
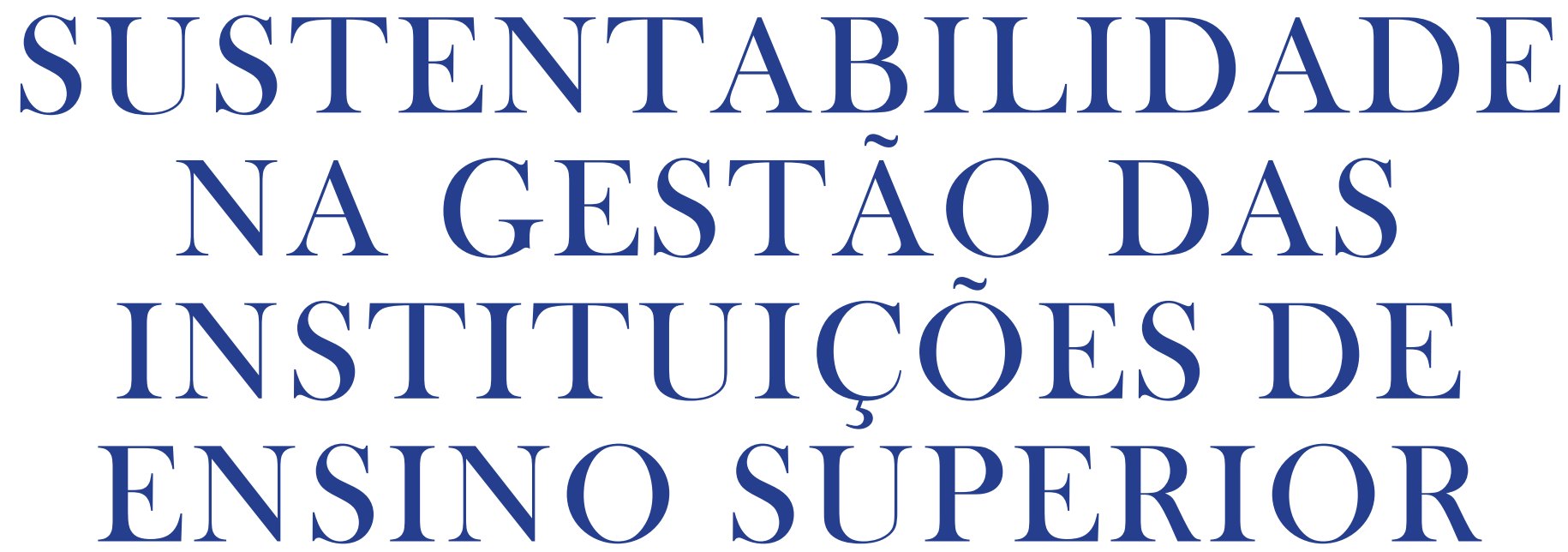

SUSTAINABILITY PROGRAMS IN THE MANAGEMENT OF HIGHER EDUCATION INSTITUTIONS

PROGRAMAS DE SOSTENIBILIDAD EN LA GESTIÓN DE LAS INSTITUCIONES DE EDUCACIÓN SUPERIOR

Irene Carniatto

Doutora em Engenharia Floresta pela UFPR. Docente do Programa de PósGraduação em Desenvolvimento Rural Sustentável da UNIOESTE.

\section{Elio Jacob Hennrich Junior}

Mestrando pelo Programa de Pós-Graduação em Desenvolvimento Rural Sustentável da UNIOESTE.

\section{Jaqueline Grasiele de Oliveira Mota}

Graduanda em Ciências Biológicas pela UNIOESTE.

Programa de Pós-Graduação em Desenvolvimento Rural Sustentável Universidade Estadual do Oeste do Paraná (UNIOESTE) Marechal Cândido Rondon - PR - Brasil 
Endereço:

Centro de Ciências Agrárias Rua Pernambuco, 1777 Marechal Cândido Rondon - PR CEP 85960-000

E-mails: irenecarniatto@gmail.com elio_jacob@hotmail.com jaquelinegomota@gmail.com Resumo: As instituições de Ensino Superior são, por princípio, geradoras de conhecimentos, formadoras de profissionais e cidadãos para todas as comunidades. Em tempo da maior crise ambiental de nossa era, as universidades e as faculdades têm formado profissionais e cidadãos conscientes e preparados para compreender, gerir e apresentar soluções para esta crise socioambiental que vivemos? Neste artigo são apresentados os dados da pesquisa desenvolvida na Universidade Estadual do Oeste do Paraná - (UNIOESTE), Cascavel, Paraná, uma pesquisa internacional denominada Projeto RISU - "Definición de indicadores y evaluación de los compromisos con la sostenibilidad en Universidades Latinoamericanas". O estudo demonstrou que a universidade apresenta uma grande inserção social em sua região e desenvolve mais de uma centena de projetos sobre sustentabilidade, educação ambiental e meio ambiente, mas ainda não possui uma política integrada em seu plano estratégico ou de desenvolvimento institucional, necessitando reestruturar as políticas articuladas pelos eixos sustentabilidade, educação ambiental e meio ambiente.

Palavras-chaves: Gestão. Universidades Sustentáveis. Educação Ambiental.

Abstract: Higher education institutions are, in principle, generators of knowledge, and trainers of professionals and 
citizens for all communities. In this era of environmental crisis, are universities and colleges training professionals and citizens who are aware, and prepared to understand, manage and present solutions for the environmental crisis we are going through? This paper presents the results of an international survey developed at the State University of West Paraná - UNIOESTE, Cascavel, Paraná, called the RISU Project "Definition of indicators and evaluation of the commitment to sustainability in Latin American Universities". The study showed that although the University is closely involved with the society in the region, developing more than a hundred projects on sustainability, environmental education and the environment, its strategic plan does not have an integrated policy for the institutional development of the University. A restructuring of policies in the areas of sustainability, environmental education and environment is therefore needed.

Keywords: Management. Sustainable Universities. Environmental Education.

Resumen: Las instituciones de Educación Superior son, por principio, generadoras de conocimientos, formadoras de profesionales y ciudadanos para todas las comunidades. En tiempos de la mayor crisis ambiental de nuestra era, ¿las universidades y las facultades han formado profesionales y ciudadanos conscientes y preparados para comprender, administrar y presentar soluciones para esta crisis socioambiental que vivimos? En este artículo se presentan los datos de la investigación desarrollada en la Universidad del Estado del Oeste de Paraná - (Unioeste), de Cascavel, Paraná, una investigación internacional denominada Proyecto RISU - "Definición de indicadores y evaluación de los compromisos con la sostenibilidad en Universidades Latinoamericanas". El estudio demostró que la universidad presenta una importante inserción social en su región y desarrolla más de un centenar de proyectos sobre sostenibilidad, educación ambiental y medio ambiente, pero todavía no posee una política integrada 
en su plan estratégico o de desarrollo institucional, y necesita reestructurar las políticas articuladas por los ejes sostenibilidad, educación ambiental y medio ambiente.

Palabras clave: Gestión. Universidades Sostenibles. Educación Ambiental.

INTRODUÇÃO

\section{PANORAMAS DA CRISE SOCIOAMBIENTAL ATUAL}

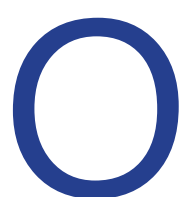

desenvolvimento da economia, o crescimento demográfico e a globalização, juntamente com a tecnologia, trazem consigo alterações no cotidiano, nos hábitos diários e nos meio de produção e de consumo das pessoas. As consequências desses procedimentos são diversas, uma delas seria o aumento na produção e no descarte dos resíduos sólidos, em massa, numa grande variedade, produzida principalmente nas grandes áreas urbanas, resíduos esses que levam em sua composição materiais sintéticos danosos ao meio ambiente e a toda sua estrutura, incluindo a saúde humana (GOUVEIA, 2012).

A natureza fez diversas vítimas com sua fúria, que nada mais é uma resposta de efeito boomerang, seguindo a antiga teoria comprovada cientificamente por Newton, quando disse que "toda ação gera uma reação". A resposta do meio ambiente vem nos diversos infortúnios ambientais da atualidade, fazendo a sociedade parar e pensar procedimentos para amenizar e, se possível, auxiliar na preservação e na restruturação do ambiente já destruído.

Deparamo-nos, então, com as dificuldades de se ter uma sociedade sustentável, devido à forte dependência da extração dos recursos naturais, para o desenvolvimento econômico, em que não há o equilíbrio de uma preservação ambiental aliada ao avanço econômico dos países.

Segundo o documento Carta da Terra (ONU, 2002, p. 1):

Devemos somar forças para gerar uma sociedade sustentável global baseada no respeito pela natureza, nos direitos humanos universais, na justiça econômica e numa cultura da paz. Para chegar a este propósito, é imperativo que nós, os povos da Terra, declaremos nossa responsabilidade uns para com os outros, com a grande comunidade da vida, e com as futuras gerações. 
A raça humana deve ser capaz de entender que agredir o meio ambiente põe em risco a sobrevivência de sua própria espécie e refletir que o que está em questão não é uma causa nacional ou regional, mas sim a existência da humanidade. É a vida que está em jogo. Não existe o homem sem algum ecossistema (KRAEMER, M. E. P.; MARTINS, J.G, 2004).

SegundoMayor,oensinodesempenhaumpapelfundamental paraaimplementação e estruturação da Sustentabilidade, "devemos estar preparados, em todos os países, para remodelar o ensino, de forma a promover atitudes e comportamentos que sejam portadores de uma nova cultura da sustentabilidade" (1998, p. 46).

A Prática da Educação Ambiental vem crescendo no meio social e junto vem a consciência da necessidade de termos padrões sustentáveis ao longo de nosso cotidiano, mostrando a sua essencialidade em todos os domínios coletivos, acabando por envolver o espaço da Educação, setor fundamental nessa troca de conhecimentos. São exemplos as instituições de Ensino Superior que estão elaborando pesquisas, a fim de tornar real a política ambiental no seu espaço de Ensino. Contudo, são limitadas as ações observadas nas Instituições de Ensino Superior, que têm por função ensinar e conscientizar seus acadêmicos, futuros cidadãos críticos, sobre a importância de uma ação ambiental para o futuro (TAUCHEN; BRANDLI, 2006). As Universidades e demais Instituições de Ensino Superior precisam praticar aquilo que constroem como conhecimento, e demonstrar ser capazes de iniciar a trajetória rumo à sustentabilidade.

O Brasil, país de ampla diversidade cultural e social, possui características distintas em cada região, em relação aos hábitos, aos costumes, à destinação de recursos financeiros, além da realidade socioambiental de cada comunidade. Portanto, devemos levar em consideração as características existentes de cada região, para propormos políticas ambientais coerentes com a realidade social local, de cada uma delas, para obtermos a efetivação com êxito do projeto de política de sustentabilidade.

Faz-se necessário, portanto, intensificar estudos, pesquisas e debates sobre a problemática ambiental atual, com o objetivo de haver uma abrangência de todos os setores, alcançando a sociedade na sua forma totalitária, com o intuito que todo cidadão possa ter acesso a esses conhecimentos (SCHNEIDER, 2000).

A partir da demanda apresentada das universidades de diversos países, tendo à frente a ARIUSA (Alianza de Redes Iberoamericanas de Universidades por la 
Sostenibilidad y el Ambiente), aliada ao Projeto RISU - "Definición de indicadores y evaluación de los compromisos con lasostenibilidaden Universidades Latinoamericanas" (BENAYAS, 2014), foi realizada uma pesquisa para definir indicadores para a avaliação das políticas de sustentabilidade das universidades latino-americanas.

O projeto tem por objetivo realizar uma pesquisa sobre o estado de gestão de políticas de sustentabilidade e/ou intensificar a sustentabilidade e a responsabilidade social nas universidades para que a sustentabilidade ocorra no seu cotidiano, por meio dos seus programas de ensino, gestão e espaço físico, alcançando uma mobilização geral e conseguindo uma preservação do ambiente em que se está inserido.

A UNIOESTE participou da pesquisa como membro da ARIUSA, por meio da Rede Sul Brasileira de Educação Ambiental (REASul), partindo dos resultados obtidos desta pesquisa, com um questionário comum, aplicado às universidades integrantes do projeto. E a partir da mobilização, da discussão e dos dados levantados, desenvolveu ações e uma pesquisa paralela para avaliar quais ações já existem e como estão articuladas e fundamentadas as Políticas Ambientais da UNIOESTE. Essa análise foi realizada a partir dos dados de pesquisa obtidos e articulada ao resultado da pesquisa das Ações Ambientais desenvolvidas pela UNIOESTE.

O Laboratório de Bacias Hidrográficas e Educação Ambiental (LABHEA) atuou na articulação na UNIOESTE da pesquisa do Projeto da RISU, o qual teve a participação de 65 universidades, localizadas em 10 países em toda a América Latina e Caribe. O projeto teve por objetivo realizar uma pesquisa sobre o estado de gestão de políticas de sustentabilidade e/ou intensificar a sustentabilidade e a responsabilidade social nas universidades para que a sustentabilidade ocorra no seu cotidiano, por meio dos seus programas de ensino, gestão e espaço físico, alcançando uma mobilização geral e conseguindo uma preservação do ambiente em que se está inserido.

Por meio da participação na pesquisa da RISU, a UNIOESTE objetivou compreender a realidade ambiental da universidade, partindo dos resultados obtidos por meio da pesquisa, com um questionário comum, aplicado às universidades integrantes da Rede ARIUSA, tendo também como fundamento os resultados percebidos a partir de uma análise das Ações Ambientais desenvolvidas pela UNIOESTE e a partir da análise promover o planejamento de estratégias de ações de sustentabilidade, a fim de formar universitários comprometidos com a sustentabilidade local e planetária. 
Os procedimentos realizados acerca da pesquisa foram desenvolvidos por meio do projeto ARIUSA, cujos resultados basearam-se na aplicação do Questionário do Projeto RISU na UNIOESTE.

O questionário RISU/ARIUSA possui 114 indicadores, separados em 11 diferentes áreas temáticas ou dimensões para implementar as Universidades Sustentáveis.

Considerando as diversas dimensões da pesquisa, na UNIOESTE o questionário foi dividido em quatro partes, cada parte foi encaminhada para o setor responsável, de acordo com as atribuições de cada setor, sendo áreas de cunho administrativo e pedagógico da universidade UNIOESTE, sendo eles: Política de sustentabilidade; Consciência e participação pela Pró-Reitoria de Planejamento (PROPLAN); Docência pela Pró-Reitoria de Graduação (PROGRAD), Docência, Investigação e Transferência pela Pró-Reitoria de Pesquisa e Pós-Graduação (PRPPG); as dimensões Responsabilidade socioambiental; Urbanismo; Mobilidade; Biodiversidade; e Contratação responsável pela Pró-Reitoria de Administração e Finanças (PRAF) e a Seção de Manutenção e Conservação da Reitoria respondeu sobre Energia; Água; e Resíduos, as quais foram respondidas pelas equipes técnicas e autoridades responsáveis de cada área.

O questionário respondido foi postado no site RISU, para se juntar aos demais questionários respondidos por mais de 80 universidades de toda América Latina.

\section{RESULTADOS E DISCUSSÃO}

No presente artigo, analisamos seis áreas temáticas que possuem uma relevância no atual panorama da universidade: Indicadores de Sustentabilidade; Indicadores de Consciência e Participação ambiental; Indicadores de Docência; Indicadores de Gestão Energética; Indicadores de Gestão Hídrica; Indicadores de Gestão de Resíduos.

\section{POLÍTICAS DE SUSTENTABILIDADE}

O primeiro eixo analisado foi o de políticas de sustentabilidade, o qual possui 15 indicadores e que pode ser observado na Figura 1. 
Figura 1: Indicadores de Sustentabilidade

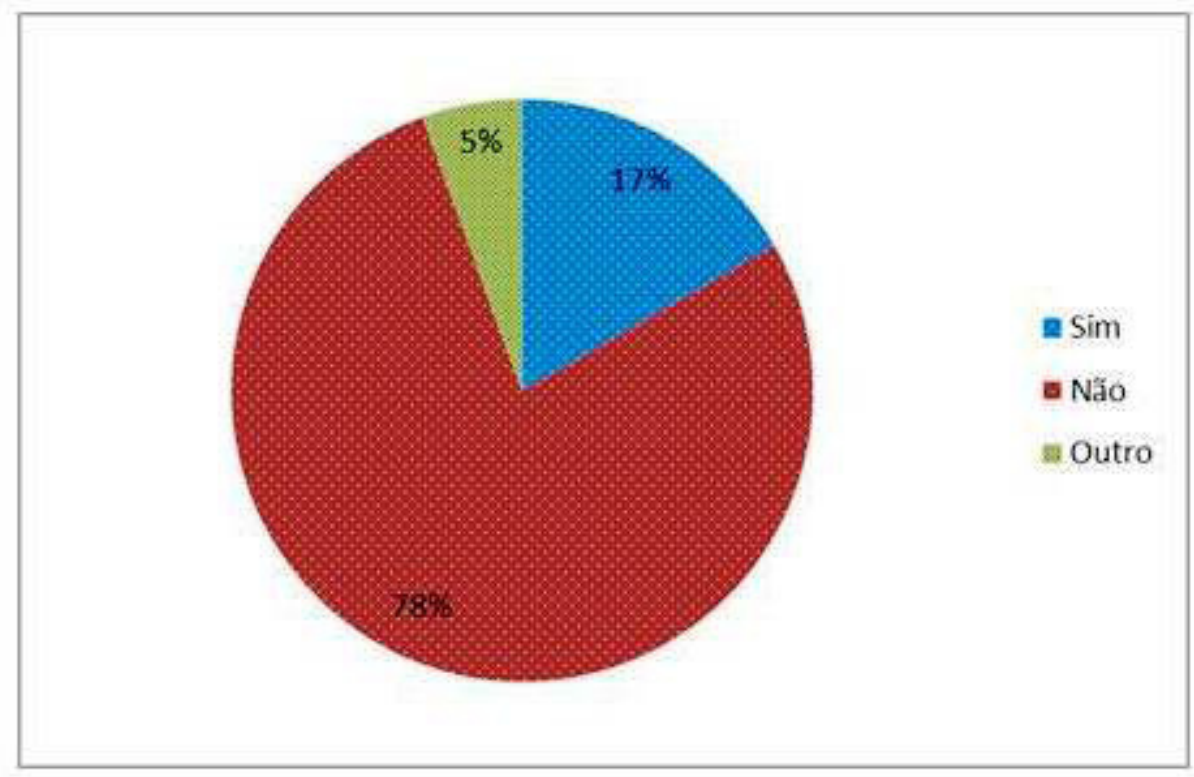

Fonte: Dados da UNIOESTE levantados na Pesquisa do Projeto RISU/ARIUSA (2014).

Observamos que os três indicadores positivos, que obtiveram respostas afirmativas, demonstram que na universidade existe um documento que norteia as políticas de sustentabilidade e meio ambiente e que o mesmo está integrado com o Plano de Desenvolvimento Institucional da UNIOESTE (PDI 2013-2017). A universidade ainda participa de redes nacionais e internacionais de Educação Ambiental e Sustentabilidade (REBEA, REASUL, REA-PR e ARIUSA e RISU) representada pelo LABHEA.

Porém a universidade ainda trabalha estas políticas de uma maneira isolada de Sustentabilidade e ainda não possui a maioria de seus respectivos indicadores, como coordenadorias específicas, espaços físicos para a implementação e gestão das políticas de sustentabilidade, tampouco possui algum estudo de impacto ambiental de suas atividades de modo integral ou parcial (cobrindo todas as suas atividades ou todos os elementos de impacto, tais como energia, água, resíduos, etc.), ou de modo parcial, consequentemente também não possuindo indicadores de acompanhamento/monitoramento relacionados com o impacto ambiental ou do plano de ação ambiental institucional.

Perante a análise das diversas concepções de desenvolvimento sustentável, Frey (2000), apresenta de modo enfático a abrangência do modelo político-administrativo e o papel do Estado. Em seu trabalho, o autor argumenta no sentido de sustentar a ideologia de que: 
[...] o desafio do desenvolvimento sustentável é, antes de tudo, um problema político e de exercício de poder, que coloca em pauta a questão das instituições políticoadministrativas, da participação e do processo político. (FREY, 2000, p.116).

O estudo demonstrou a falta de uma política integrada, que apresente coerência, consistência, que permeie todas as dimensões da sustentabilidade, que possa estabelecer objetivos, metas e ações necessárias à correta administração dos recursos e, principalmente, à formação de profissionais comprometidos com a sustentabilidade e a melhoria da qualidade de vida do planeta, independente da carreira profissional em que está se formando.

\section{CONSCIÊNCIA E PARTICIPAÇÃO AMBIENTAL}

O segundo eixo analisado foi o de Consciência e Participação Ambiental, que possui 12 indicadores conforme mostra a Figura 2.

Analisando esse eixo temático, podemos ver um aumento na presença do percentual de indicadores positivos e que há a existência de incentivos monetários (bolsas) para acadêmicos se dedicarem às atividades relacionadas ao meio ambiente e à sustentabilidade e, ainda, existem associações ou entidades não institucionais, formadas por estudantes ou outros membros da comunidade universitária que se dedicam a realizar atividades correlacionadas com o tema.

Figura 2: Indicadores de Consciência e Participação Ambiental

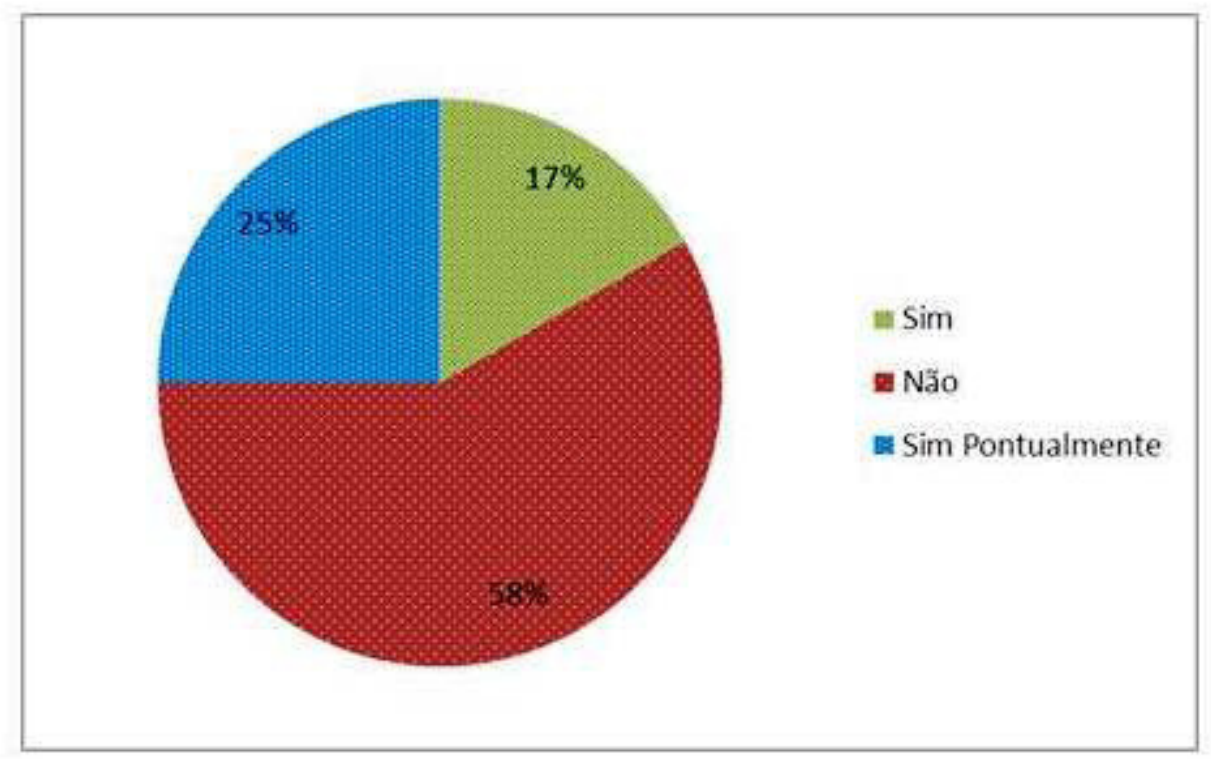

Fonte: Dados da UNIOESTE levantados na Pesquisa do Projeto da RISU/ARIUSA (2014). 
Os outros dois resultados positivos foram apenas parciais, pois consideramos que houve apenas ações pontuais na oferta para a participação da comunidade universitária em programas de caráter socioambientais, realizados fora da sua universidade e também organizados em cursos de extensão universitária em temática ambiental ou de sustentabilidade.

Para mapear as ações socioambientais desenvolvidas pela UNIOESTE, em pesquisa realizada por Steding e Carniatto (2014):

Figura 3: Total de projetos realizado nos campi no período de 2002 a 2014

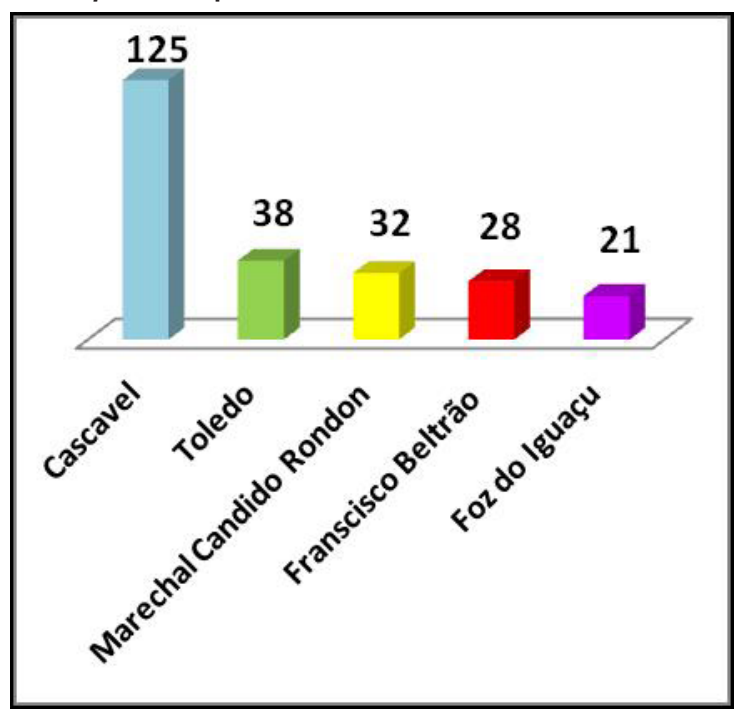

Figura 4: Projetos em andamento nos campi

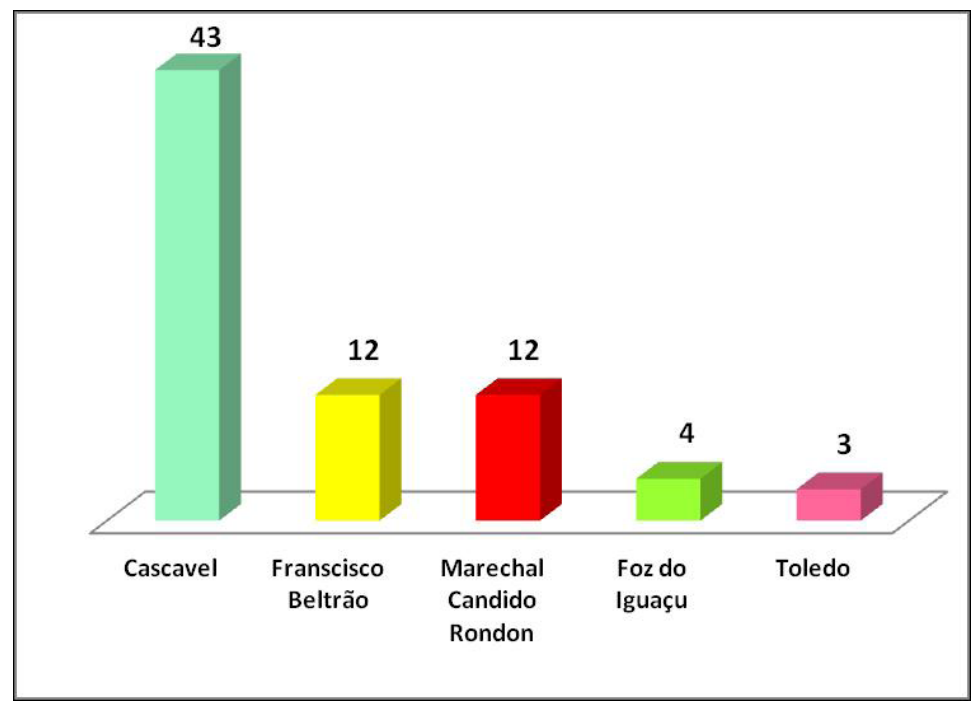

Fonte: Steding e Carniatto (2014).

Constatamos que, de 2002 a 2014, os 05 campi da UNIOESTE desenvolvem 244 projetos ligados aos temas ambientais. Destes, 125 são desenvolvidos no campus de Cascavel, seguido de 38 projetos em Toledo; 32 projetos, em Marechal Candido Rondon; o campus de Francisco Beltrão realizou 28 projetos e 21 projetos realizados pelo campus de Foz do Iguaçu. Desse total, apenas 74 se encontram em andamento, conforme os dados apresentados nas figuras 3 e 4.

A pesquisa representa que, por meio de suas ações, a UNIOESTE tem contribuído significativamente para a produção de conhecimento, melhoria de processos, desenvolvimento de produtos e melhoria da qualidade de vida das comunidades que habitam as regiões Oeste e Sudoeste do Paraná.

Quanto à categoria dos projetos desenvolvidos, apuramos que, do total, 43 projetos (18\%) foram de Educação Ambiental, 73 (30\%) projetos Socioambientais e 128 sobre Meio Ambiente, representando 52\% do total (Figura 5). 
Figura 5: Total de projetos desenvolvidos na UNIOESTE, segundo as categorias dos Projetos

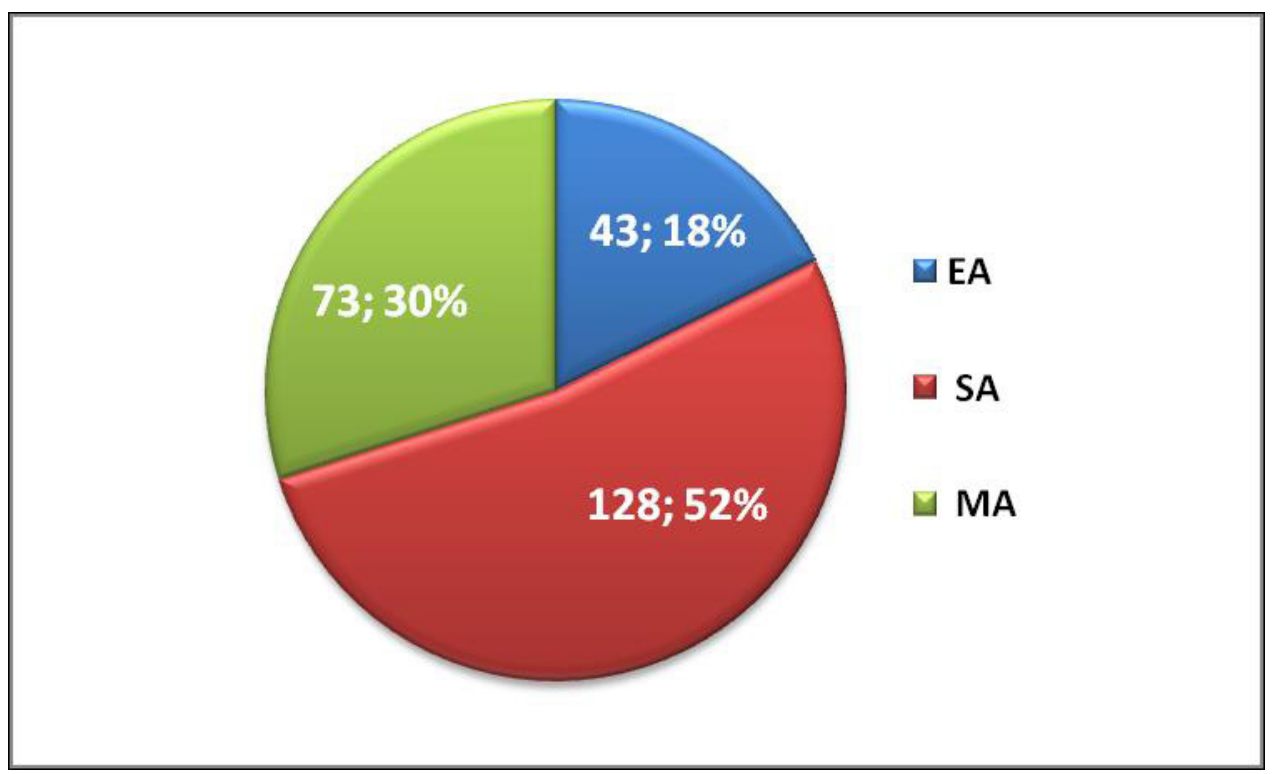

Fonte: Steding e Carniatto (2014).

Porém, com a presente pesquisa e a pesquisa citada, notamos que ainda há a necessidade de estabelecer melhores canais de comunicação com a comunidade universitária, procurando fomentar ações extracurriculares, como atividades de pesquisa e extensão relacionadas ao tema sustentabilidade e que tenham impactos diretos na sustentabilidade local e na UNIOESTE.

Segundo Oliveira (2011), a conscientização global da crise ambiental atual exige uma cidadania participativa, que compreende a ação conjunta do Estado e da coletividade na proteção ambiental. Não podemos adotar uma concepção individualista acerca da preservação ambiental, sem cooperação e desprovida de responsabilidades sociais. A participação é um mecanismo a favor da sustentabilidade, pois proporciona uma mudança de comportamento. O cidadão que participa se torna mais consciente da sua atribuição no planeta em que vive, compreende as questões ambientais e acerca de seus direitos e deveres. Quando as pessoas desenvolvem a consciência de que fazem parte de um todo e que suas ações e também suas omissões em relação ao meio ambiente, assim, como os demais seres humanos, trazem consequências à qualidade de vida e ao bem-estar geral, passam a adotar outra postura. 


\section{DOCÊNCIA: FORMAÇÃO EM SUSTENTABILIDADE, NO ÂMBITO DO ENSINO UNIVERSITÁRIO}

No eixo Docência o questionário avaliou o grau de implementação da formação em sustentabilidade no âmbito do ensino universitário.

Neste eixo, conforme mostra a Figura 6, observamos uma maior quantidade de respostas positivas em relação a atividades de política de sustentabilidade nas atividades docentes. A perspectiva de sustentabilidade é incorporada em ao menos $10 \%$ dos currículos dos cursos ofertados na instituição, alguns dos conteúdos sobre sustentabilidade foram incluídos de forma específica e adaptados no contexto de cada carreira.

A universidade oferta programas de pós-graduação específicos sobre meio ambiente, bem como projetos de conclusão de curso relacionadosà sustentabilidade e também realiza formações continuadas com ênfase na Educação Ambiental aos docentes, fortalecendo o contexto de sustentabilidade no ensino.

Figura 6: Indicadores de Docência

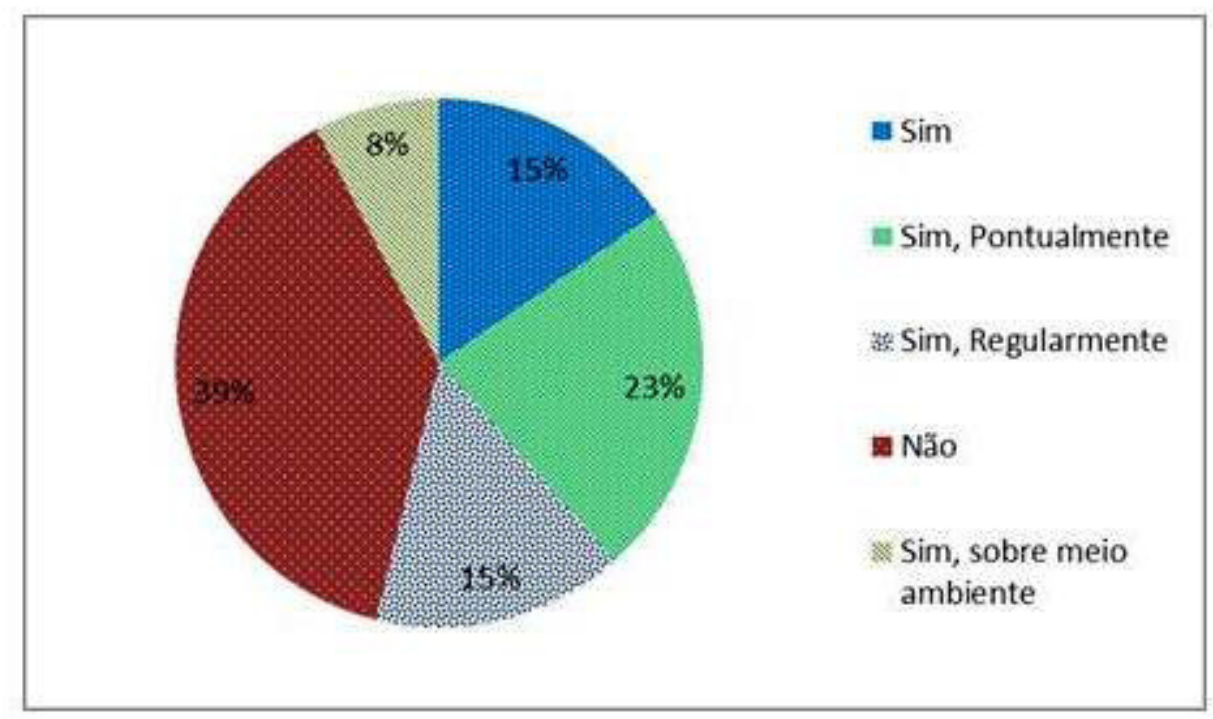

Fonte: Dados da UNIOESTE levantados na Pesquisa do Projeto da RISU/ARIUSA (2014).

As respostas negativas são em relação à inexistência de carreiras profissionais ofertadas com ênfase na sustentabilidade, além da inexistência de uma comissão ou grupo técnico encarregado de assessorar os centros ou os departamentos na adaptação dos currículos para introduzir neles critérios e conteúdos sobre sustentabilidade. 
É essencial que esses currículos dialoguem entre si, trazendo um ponto de vista transdisciplinar a seus trabalhos. Segundo Demajorovic (2003, p.175-178):

[...]o desenvolvimento de uma visão sistêmica, focada no conhecimento socioambiental, pode modificar os movimentos organizacionais e, com isso, a teoria do aprendizado organizacional relacionado aos aspectos socioambientais pode auxiliar as instituições em sua busca pela sustentabilidade.

\section{ENERGIA, ÁGUA E RESÍDUOS}

No eixo Energia, o questionário procurou avaliar a existência de atuações de economia e eficiência energética na universidade, bem como o grau de desenvolvimento de energias renováveis e políticas de sensibilização sobre a economia energética (Figura 7).

No quesito iluminação e climatização no campus, obtivemos resposta negativa em relação à existência de algum plano específico que trate da questão de Energia da universidade, bem como a inexistência de um sistema de controle de consumo de energia.

A instituição também não possui qualquer instalação de energia renovável (solar térmica, solar fotovoltaica, eólica, geotérmica ou caldeiras de biomassa). Obtivemos resposta negativa também, quando questionamos se são realizadas atividades de sensibilização e conscientização sobre a economia de energia ou as energias renováveis no âmbito da própria universidade.

Figura 7: Indicadores do eixo Energia

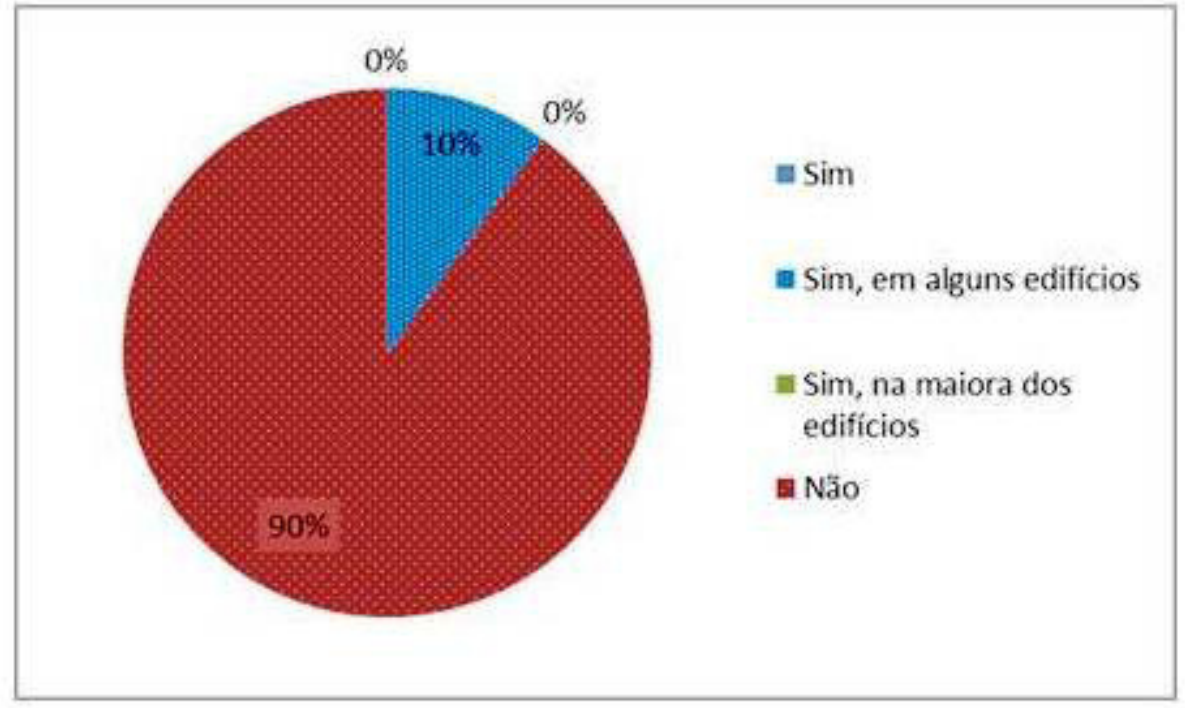

Fonte: Dados da UNIOESTE levantados na Pesquisa do Projeto da RISU/ARIUSA (2014). 
Contudo, a menor porcentagem observada no gráfico, de resposta positiva parcial, mostra ações por meio de medidas para reduzir o consumo em iluminação no interior e no exterior de alguns dos edifícios do campus, sendo eles luminárias de baixo consumo e detectores de presença.

A partir do eixo temático Água, obtemos resultados por meio da avaliação da eficiência na gestão da água, demonstrados na Figura 8.

Figura 8: Indicadores do eixo Água

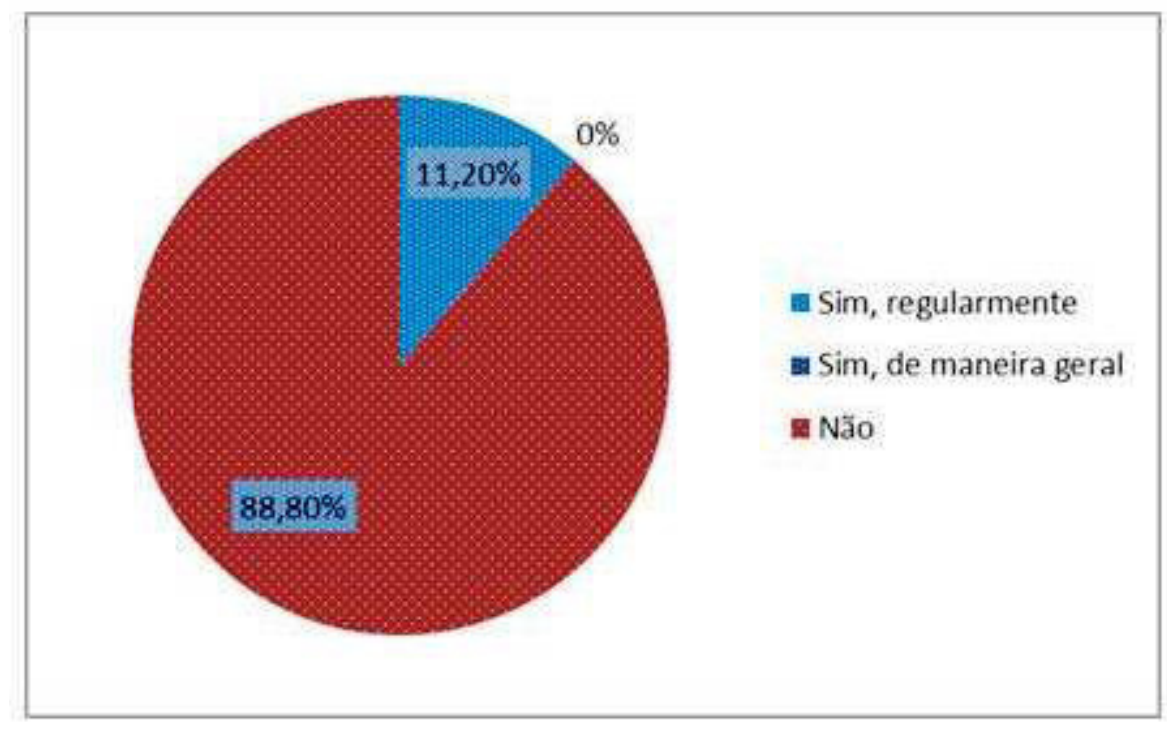

Fonte: Dados da UNIOESTE levantados na Pesquisa do Projeto da RISU/ARIUSA (2014).

A UNIOESTE não possui programas específicos destinados à economia e à reutilização de água, bem como controle e monitoramento do consumo. Os dados nos mostram a inexistência de um sistema próprio de depuração da carga poluente das águas com resíduos produzida na instituição, alem disso, os lavatórios e os sanitários não possuem um sistema de economia de água; a universidade sofre também com a falta de um projeto próprio de conscientização a favor da economia de água.

O percentual positivo nas respostas é relativo ao incentivo realizado ao uso de bebedouros, a fim de reduzir a produção de copos plásticos em grande parte dos edifícios da UNIOESTE.

O último eixo é respectivo aos Resíduos (Figura 9), no qual avaliamos a política da UNIOESTE em relação à gestão dos resíduos, contemplando, tanto a redução como a coleta seletiva e seu manejo dentro da universidade.

As respostas positivas são em relação, também, aos processos de coleta seletiva e manejo dos resíduos recicláveis gerados. São realizadas diversas atividades de 
sensibilização e conscientização sobre a redução, a coleta seletiva e a gestão de resíduos, perigosos ou urbanos, não com um caráter articulado e continuado, mas de forma pontual, acompanhada por campanhas de redução e separação de resíduos e palestras e oficinas de reciclagem.

Figura 9: Indicadores do eixo Resíduo

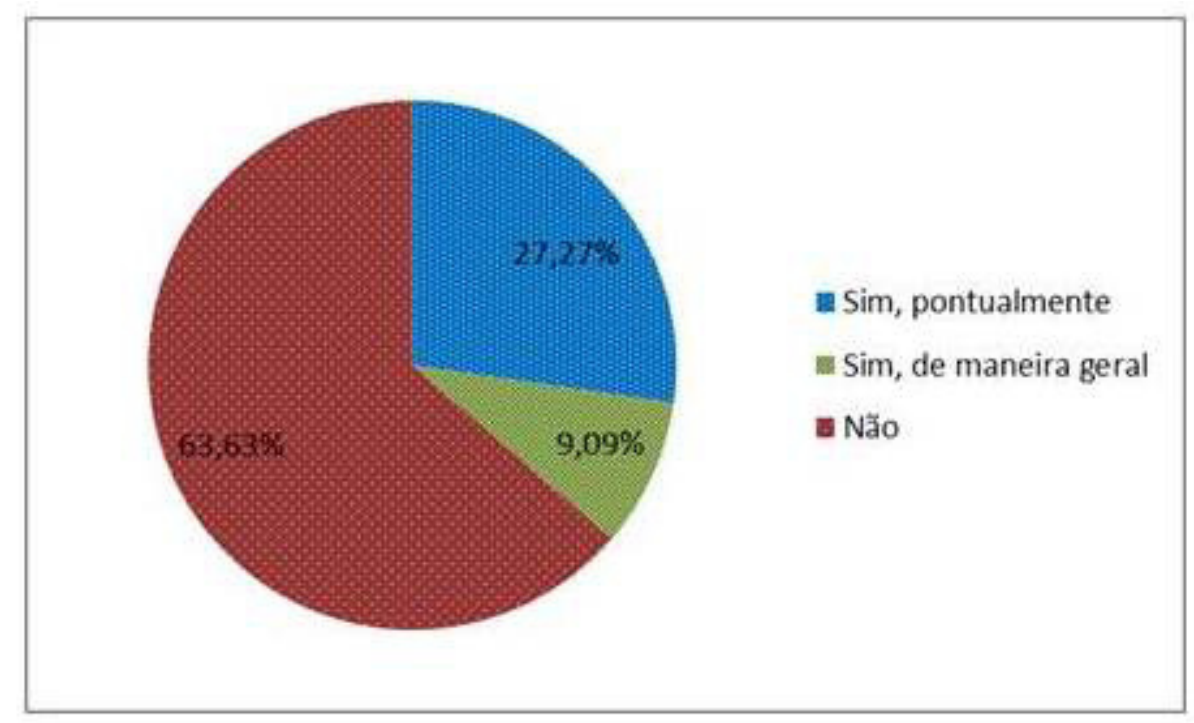

Dados: Dados da UNIOESTE levantados na Pesquisa do Projeto da RISU/ARIUSA (2014).

\section{CONSIDERAÇÕES FINAIS}

A situação de desequilíbrio ambiental e as consequências do aquecimento global tão alarmante que vemos hoje estão a mostrar que todas as instituições e cada cidadão necessitam rever suas práticas e investir na sustentabilidade, principalmente as instituições de ensino superior, que são formadoras dos profissionais que atuam em todas as áreas do mercado.

No entanto, o estudo realizado demonstra que a UNIOESTE apresenta uma grande inserção social em sua região, e que desenvolve mais de uma centena de projetos sobre sustentabilidade, educação ambiental e meio ambiente, mas ainda não possui uma política integrada em seu plano estratégico o de desenvolvimento institucional da universidade. Nos cursos tanto de graduação quanto de mestrados e doutorados, a maioria possui apenas conteúdos isolados sobre os princípios da sustentabilidade, não estando os seus Projetos Políticos Pedagógicos e Planos das disciplinas articulados pelos eixos sustentabilidade, educação ambiental e meio ambiente, apontando a necessidade de que a universidade reformule seu Programa de Desenvolvimento Institucional, Planos 
estratégicos de Administração, Ensino, Pesquisa e Extensão, Programas dos Cursos e Planos das Disciplinas, tendo como eixo principal os princípios, os conteúdos e as ações de gestão para tornar esta uma Universidade Sustentável.

REFERÊNCIAS

DEMAJOROVIC, Jacques. Sociedade de risco e responsabilidade socioambiental: perspectivas para a educação corporativa. São Paulo: Editora Senac São Paulo, 2003.

FREY, K. Políticas Públicas: Um debate conceitual de reflexões referentes à prática da análise de políticas públicas no Brasil. In: Planejamento e Políticas Públicas, n. 21, Brasília: Instituto de Pesquisa Econômica Aplicada, 2000.

GOUVEIA, N. Resíduos sólidos urbanos: impactos socioambientais e perspectiva de manejo sustentável com inclusão social. Ciência \& Saúde Coletiva. Vol.17 no.6 Rio de Janeiro Jun. 2012. Disponível em: http://www.scielosp.org/scielo.php?script=sci_arttext\&pid=S1413-81232012 000600014\&lng=pt\&nrm=iso\&tlng=pt. Acesso em: 05/02/2014.

KRAEMER, M. E. P. \& MARTINS, J.G. Educação a Distância no Ensino Superior: um olhar para a Sustentabilidade. 2004. Disponível em: http://www.abed.org.br/ congresso2004/por/htm/131-TC-D2.htm. Acesso em: 06/02/2015.

MAYOR, F. Preparar um futuro viável: ensino superior e desenvolvimento sustentável. In: Conferência mundial sobre o ensino superior. Tendências de educação superior para o século XXI. Anais da Conferência Mundial do Ensino Superior. Paris: 1998.

OLIVEIRA, M, C; Informação e participação como instrumentos para a sustentabilidade. 2011. Disponível em: http://www.unimep.br/phpg/ mostraacademica/ anais/9mostra/5/165.pdf. Acesso em: 24/02/15.

ONU. Organização das Nações Unidas. Carta da Terra, 2002.

SCHNEIDER, E. Gestão ambiental municipal: preservação ambiental e o desenvolvimento sustentável. In: Encontro Nacional de Engenharia de Produção, São Paulo, 2000. Anais. São Paulo: EPUSP. 2000.

STEDing, A., CARNiATtO, I. Mapeamento das Ações Ambientais e Projetos de Educação Ambiental e Socioambientais na Universidade Estadual do Oeste do Paraná In: O Ensino de Ciência e Matemática no Espaço Escolar. 1. ed. Curitiba: Editora CRV, 2015, v.1, p. 229-250.

TAUCHEN, J.; BRANDLI, L. L. A gestão ambiental em instituições de ensino superior: modelo para implantação em campus universitário. Gestão \& Produção. V.13, n.3, p.503-515, set.-dez. 2006. Disponível em: http://www.scielo.br/pdf/gp/v13n3/11.pdf. Acesso em: 05/02/2015.

Artigo recebido em março de 2015 Aprovado em abril de 2015 